Dr Hamdy Hefny, Central Metallurgical Research and Development Institute (CMRDI), Egypt; Utilization of Phosphogypsum for Heavy Metals Immobilization in Contaminated Soil and Extraction of Useful Materials

https://iupac.org/2020-green-chemistry-for-life-research-grants-foryoung-scientists/

John Macor is Awarded the 2020 IUPAC-Richter Prize

he 2020 IUPAC-
Richter Prize
in Medicinal
Chemistry has been
awarded to John
Macor, PhD, Global
Head Integrated Drug
Discovery, Sanofi.

Dr. Macor received the award in recognition of his outstanding creative contributions in the field of medicinal chemistry research on drugs for

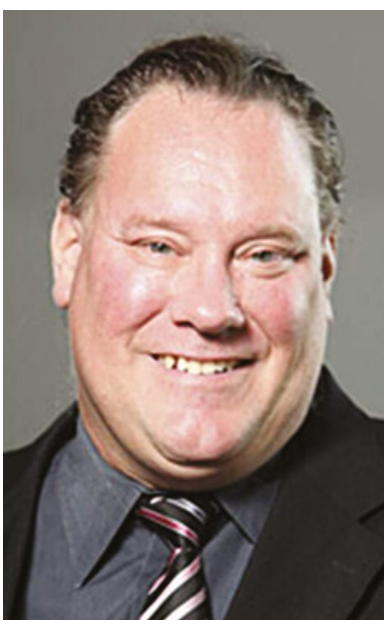
the treatment of migraine. John's improvements to the triptan core structure fueled the discovery of an effective drug within the class that displayed superior pharmacokinetics compared to the flagship triptan drug at that time, sumatriptan. John Macor is a co-discoverer of two advanced clinical candidates within a new class of small-molecule anti-migraine drugs, the calcitonin gene-related peptide (CGRP) inhibitors. One of these is currently under approval review by the FDA. John Macor's contributions to drug design and consistent support of medicinal chemistry have earned him this prestigious prize.

The IUPAC-Richter Prize, comprising a plaque and a check for USD 10 000, will be presented at the XXVI EFMC-ISMC International Symposium on Medicinal Chemistry to be held in Basel, Switzerland, 6-10 September 2020. The plaque will be signed by Christopher M.A. Brett, President of IUPAC, Gábor Orbán, CEO of Gedeon Richter Plc (Budapest, Hungary), and János Fischer, Chair of the IUPAC-Richter Prize selection committee. John Macor will present an acceptance lecture at this Symposium and a second lecture at the 37th ACS National Medicinal Chemistry Symposium to be held in New York (28 June - 1 July 2020).

Dr. Macor earned his Ph.D. degree at Princeton
University with Professor E.C. Taylor in 1986. His career has spanned four decades and four different pharmaceutical companies. John began his career at Pfizer in 1986 where he was engaged in a variety of CNS drug discovery efforts. He moved to Astra Arcus in 1994 and focused on cholinergic drug discovery, John then moved to Bristol-Myers Squibb in 1997, where he started in cardiovascular research before transitioning to neuroscience in 2001 and immunoinflammatory research in 2013. In October 2016, he accepted the role as Global Head Integrated Drug Discovery for Sanofi.

This year marks the eighth occasion of the IUPAC-Richter Prize, which was established in 2005 by IUPAC and Richter PLC. Awarded biannually, the awardee is announced by IUPAC following nominations and the decision of an independent international Selection Committee. The lecture in which the prize is awarded occurs alternatively in Europe and in the United States. The previous awardees were: 2006, Malcolm FG Stevens (UK); 2008, Jan Heeres (Belgium); 2010, Arun Ghosh (USA); 2012, Stephen Hanessian (Canada); 2014, Helmut Buschmann (Germany); 2016, Michael Sofia (USA); and 2018, Peter Grootenhuis (USA).

The Chair of the current international Selection Committee is Janos Fischer (IUPAC). The jury members are Yves Auberson (Switzerland), Jonathan Baell (Australia), Helmut Buschmann (Germany), Wayne Childers (USA), Kazumi Kondo (Japan), David Rotella (USA), Gerd Schnorrenberg (Germany), Mike Waring (UK), and Patrick Woster (USA). The IUPAC-RICHTER Prize is recognized internationally, as demonstrated by a high number of nominations of successful and internationally renowned scientists in drug research.

For an overview of the Prize, see https://iupac.org/what-we-do/awards/ iupac-richter-prize-medicinal-chemistry/

7th Polymer International-IUPAC Award goes to Guihua Yu

\footnotetext{
he Editorial Board of Polymer International and the IUPAC Polymer Division are delighted to announce that Guihua Yu (University of Texas at Austin, USA) is the winner of the $7^{\text {th }}$ Polymer International-IUPAC award for Creativity in Applied Polymer Science.
}

This award celebrates the outstanding contributions that Professor Yu has made to polymer nanoscience and engineering. He has achieved extraordinary research accomplishments and shown remarkable 


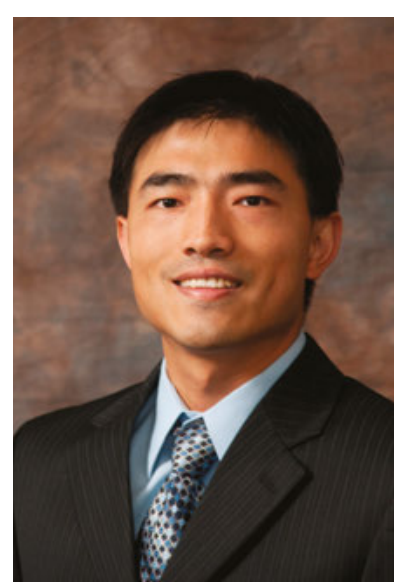

creativity and scientific scholarship in several areas of materials science.

Professor Yu has made significant contributions to synthesis and fundamental investigation of new multifunctional polymer nanostructures with novel chemical and physical properties, and their significant applications in advanced energy, sustainability and environmental technologies. A rising leader in the field of polymer science, he has authored over 150 articles in peer-reviewed journals and his work has garnered more than 19,000 citations, with 21 articles having each received over 200 citations. The work of his research group has been featured in prominent journals and global scientific news.

Professor $\mathrm{Yu}$ will give a lecture and receive this award at the World Polymer Congress (http://www. macro2020.org/), which will be held in Jeju Island, South Korea, 5-9 July 2020. The award includes $\$ 5,000$, plus travel and hotel accommodation expenses to attend MACRO 2020.

https://iupac.org/7th-polymer-international-iupac-award-goes-toguihua-yu/

\section{IUPAC-ThalesNano Prize In Flow Chemistry and Microfluidics-Call For Nominations}

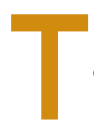

he IUPAC-ThalesNano Prize in Flow Chemistry and Microfluidics is to be awarded to an internationally recognized scientist, whose activities or published accounts have made an outstanding contribution in the field of flow chemistry, microfluidics, micro fabrication, and micro systems engineering in academia or industry. Nomination materials should be submitted by 31 May 2020 by visiting the website.

https://iupac.org/2020-iupac-thalesnano-prize-in-flow-chemistry-andmicrofluidics-call-for-nominations/

\section{Advancing Science as a Global Public Good: ISC Action Plan 2019-2021}

\section{he International Science Council's (ISC) released a new action plan for action over the next two and a half years. The document most important purpose is to form a practical framework for the ISC's work, in all of its key functions, until the end of 2021.}

The Action plan gives effect to the Council's vision and mission, contained in the high-level strategy published on the occasion of the Council's launch in 2018. In addition, it serves as a basis for active engagement with ISC members, and as a point of departure for dialogue and cooperation with partners and funders who share our objectives. The Action Plan is intended to be a living document, allowing the ISC the flexibility to respond

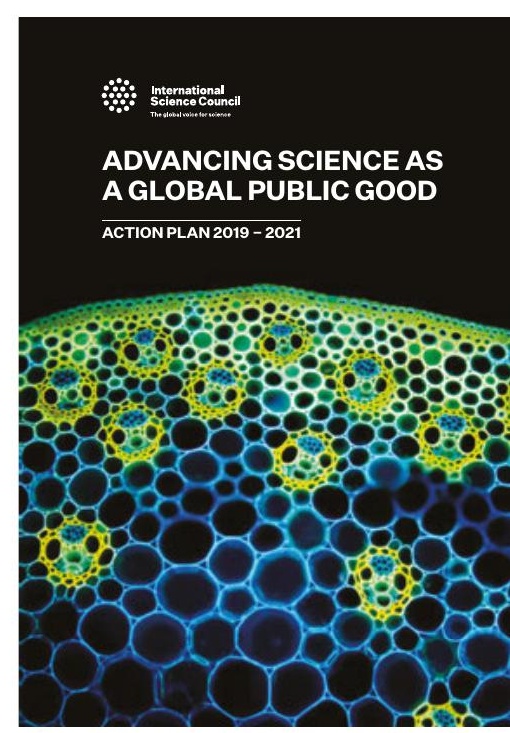
to new and emerging opportunities, and to adapt to ongoing strategic reflection and development. It will also provide a basis for continual monitoring and progress reporting to members and other stakeholders.

At the heart of the Action Plan is a selection of projects and programmes that are relevant to all scientific fields and all parts of the world. Some of these are already in progress; others are ready for development. Many encompass and build on ongoing ISC activities, including the Council's portfolio of international research programmes, scientific committees, networks, data bodies and observing systems.

Call to action: The ISC seeks partnerships with members, with other international scientific organizations, with funders and with stakeholders in the public and private sectors who are inspired by the actions presented in the Plan and who want to join ISC and who share the ambitions captured in the global call. ISC's projects and programmes cover four domains of impact: i) the 2030 Agenda for Sustainable Development; ii) The Digital Revolution; iii) Science in Policy and Public Discourse; and iv) The Evolution of Science and Science Systems.

https://council.science/actionplan/ 